\title{
Estimation of reduced life expectancy from serious occupational injuries in Taiwan
}

\author{
Jiune-Jye Ho ${ }^{\mathrm{a}, \mathrm{c}}$, Jing-Shiang Hwang ${ }^{\mathrm{b}}$, Jung-Der Wang ${ }^{\mathrm{c}, \mathrm{d}, *}$ \\ a Institute of Occupational Safety and Health, Council of Labor Affairs, The Executive Yuan, No. 99, Lane 407, \\ Henke Road, Sijhih City, Taipei County 221, Taiwan \\ ${ }^{\mathrm{b}}$ Institute of Statistical Science, Academia Sinica, No. 128, Academia Road Section 2, Taipei 115, Taiwan \\ ${ }^{\mathrm{c}}$ Institute of Occupational Medicine and Industrial Hygiene, College of Public Health, \\ National Taiwan University, No. 17, Xuzhou Road, Taipei 100, Taiwan \\ ${ }^{\mathrm{d}}$ Department of Internal Medicine, National Taiwan University Hospital, \\ No. 7, Chung-San South Road, Taipei 100, Taiwan
}

Received 28 February 2005; received in revised form 20 December 2005; accepted 28 March 2006

\begin{abstract}
This study assesses the loss of life expectancy and potential working life in Taiwan, between 1986 and 2000, from various types of occupational accidents resulting in mortality or permanent disability. The databases on occupational mortality and permanent disability were obtained from the Bureau of Labor Insurance, with this information then being linked to national death registry data to construct the survival function. A Monte Carlo simulation method was subsequently used to extrapolate the survival rate for up to 600 months, to derive the life expectancy for different types of occupational accidents leading to permanent disability $(n=81,249)$. Based upon the life table for each calendar year, the life expectancy lost by age-gender cohort was also estimated for cases of mortality $(n=20,001)$. In those cases resulting in permanent occupational disability, variations in the expected years of life lost (EYLL) were demonstrated by different occupational injuries, ranging from 7.4 to 13.6 years per case. The overall EYLL through permanent occupational disability is found to be almost identical to that of occupational mortality, with a ratio of 1.04:1. We conclude that permanent disability resulting from occupational injuries has a significant impact on society as a whole.
\end{abstract}

(C) 2006 Elsevier Ltd. All rights reserved.

Keywords: Expected years of life lost; Traumatic occupational injury; Monte Carlo simulation; Permanent disability; Health impacts

\section{Introduction}

Occupational injuries have brought about significant health impacts on society as a whole in both developing and developed countries (Zwi et al., 1996; Leigh et al., 1999). The International Labor Organization (ILO) estimated that there were approximately 335,000 annual fatalities as a direct result of occupational injuries, observing a worldwide mortality rate of 14 deaths per 100,000 workers, with the highest injury fatality rates being found in the developing countries (Takala, 1999; Herbert and Landrigan, 2000). Numerous studies have found that the costs of the broader social and economic consequences of occupational injuries are similar to the costs of cancer and heart disease treatment in the US, and greater than the costs of treatment for

\footnotetext{
* Corresponding author. Tel.: +8862 33228080; fax: +886223224660.

E-mail address: jdwang@ha.mc.ntu.edu.tw (J.-D. Wang).
}

'acquired immunodeficiency syndrome' (AIDS) (see, for example, Boden et al., 2001; Dembe, 2001; Weil, 2001; National Institute for Occupational Safety and Health, 2001; Leigh et al., 1997).

Although the total number of deaths from occupational injuries has remained high, a steady decline in mortality rates, over time, has raised interest in quantifying the burden of nonfatal injuries (Segui-Gomez and Mackenzie, 2003). In Finland, a considerable proportion of non-fatal injuries were considered minor, since they resulted in only several days of restricted activity; however, many injuries, which often involved fractures, amputation, brain injury or severe permanent disability, were found to bring extreme consequences upon society (Asikainen et al., 1996).

Over recent decades, as a direct result of advancements in new medical technologies, the lives of victims of serious injury have been significantly prolonged following their occupational accidents (McColl et al., 1997); thus, in order to achieve greater 
accuracy in calculating life expectancy, the burden of occupational injuries requires information beyond traditional methods of calculating mortality so as to acknowledge the overall impacts of non-fatal injuries (Segui-Gomez and Mackenzie, 2003). Accidents at work leading to permanent disability therefore merit attention.

In addition to the absolute count (number of cases) and rates (number of cases per time-unit worked), the notion of 'years of potential life lost' (YPLL) was first proposed as a means of quantifying the real burden of tuberculosis in the 1940s (Dempsey, 1947). This method gained further popularity for use in quantifying the burden of other diseases/injuries because of its advantage of giving a greater weight to earlier deaths (McDonnell et al., 1998). Lee (1997) also indicated that the concept of YPLL has intuitive appeal for direct comparison of the relative impacts for different causes of death. Nevertheless, the arbitrarily chosen potential limit of life was the major criticism of YPLL. Instead, the expected years of life lost (EYLL) can be calculated to reveal reduced life expectancies resulting from different injuries based on life tables (Murray et al., 2002). Furthermore, YPLL measures the impact of mortality as opposed to morbidity (Segui-Gomez and Mackenzie, 2003); thus, from this approach, the YPLL ignores those accidents leading to permanent disability, and therefore renders the estimation of insurance premiums relatively inaccurate due to the lack of information on the survival rates for occupational injuries (Thompson et al., 2002).

Throughout Taiwan's extensive period of rapid economic development, from the mid-1980s through until the end of the century, the incidence rate of occupational injuries on the island has remained higher than the incidence rates in other developed countries (Chang and Wang, 1995; Council of Labor Affairs, 2004). There appeared to be some improvement in both the frequency and severity of serious occupational injuries, as reported by different industries in Taiwan between 1983 and 1993 (Chang and Wang, 1997); however, recent labor statistics have shown that for each year between 2000 and 2002, there were in excess of 5000 claims submitted for permanent disability compensation (Bureau of Labor Insurance, 2004).

The different types of injuries resulting from various occupational accidents generally imply different strategies for prevention; it would therefore seem pertinent to explore the different health impacts resulting from different types of work-related injuries (Pratt et al., 1996; NIOSH, 2000). Information on the characteristics of each of the incidents resulting in injury may also provide the government and companies with the necessary information to enable them to implement more effective control programs (Horan and Mallonee, 2003).

This study therefore sets out with the aim of assessing the life expectancy lost from serious occupational injuries, in terms of both EYLL and 'years of potential working life lost' (YPWLL). These parameters were estimated based upon empirical examination of the differences in survival rates between affected workers and the age- and gender-matched general population. The 15-year survival data on workers with permanent disability provides excellent information on the estimation of different types of accidents resulting in occupational injuries. A comparison of the sum total of EYLL resulting from both occupational mortality and permanent disability is also undertaken in this study.

\section{Methodology}

\subsection{Study subjects}

The labor insurance scheme in Taiwan, which has been administered by the Bureau of Labor Insurance (BLI) since 1950 , is endorsed under a social insurance charter. The scheme is similar to the workers' compensation system in the US (Department of Labor, 2003), although in Taiwan, in addition to comprehensive reimbursement for medical services, the scheme also offers lump sum payments for occupational mortality or permanent disability.

The first expansion of the insurance program, in 1981, resulted in cover for all industries and all companies/firms with more than 10 employees, with the coverage being further widened, in 1988, to those firms with more than five employees. Since this program can be classified as a form of compulsory employment insurance, a total of 8.1 million insured workers were consequently covering as much as $80.4 \%$ of the total workforce in 2003 (Council of Labor Affairs, 2004).

Since the causal relationships between accidents at work and occupational injuries could only be disproved by refuting evidence provided by employers, common occupational injuries generally obtained the compensation without any difficulty. As a result, the BLI database has remained relatively comprehensive with regard to the registration of any accidents leading to occupational injuries, including those occurring outside of Taiwan.

The BLI database includes 84,436 compensation claims for permanent disability resulting from work-related injuries between the years 1986 and 2000. Of these, 3187 cases, involving migrant workers from other countries, were excluded from the analysis for lack of survival information in Taiwan. As a result, data were collected on 81,249 cases of permanent disability (96.2\% of the total), with the following information being identified; identification number (ID number); date of birth; insurance history; insurance wage; injury data including severity of disability; type of accident; part of the body affected; lump sum compensation payment from the BLI for the permanent disability.

The BLI coding system for injury classifications was also reviewed and revised in accordance with the 1992 Occupational Injury and Illness Classification System (OIICS), developed by the US Bureau of Labor Statistics (USBLS) (Toscano et al., 1996). A total of 6,411 cases displayed codes for injury types that were unclassified, blank or erroneous; all of these were categorized as 'not otherwise specified' (NOS) injuries. A total of 20,001 cases of mortality were also included in the study sample.

For every case of permanent occupational disability, the survival was tracked from the date of the onset of the injury, until December 2000. The follow-up method used involved linking the database with the national death registry to determine whether the individual involved in each case was still living in 
the year 2000. Taiwan has a computerized death registry - established by the Department of Health (DOH) - which is based upon data from death certificates that have been officially verified by the Bureau of Internal Revenue Services at the Ministry of the Interior.

A total of 2,147,272 deaths were identified between the years 1980 and 2000 (Hsieh et al., 2002); therefore, by linking the ID numbers between the two databases, those workers who had been injured at work, and who were still alive, could easily be identified. In the case of the deceased, details were extracted on the dates of death, from which the survival duration of each mortality case could then be calculated. If the ID numbers of any workers were not found in the database of the death registry, then they were considered to be still alive in December 2000. The ID numbers of the 20,001 mortality cases were also checked against the death registry database, to examine the proportional linkage with the mortality database, and thereby, its validity; as a result of this check, a total of 19,067 cases $(95.3 \%)$ were successfully linked to the death registry.

\subsection{Measures}

The Kaplan-Meier method was used to estimate the cases of survival linked to different types of occupational injuries, with a maximum follow-up of 180 months. The calculations for this method were undertaken by the life-test procedure from the SAS/STAT software 8.02 edition (SAS, 2002). Based upon the survival data from the index of cases with different injury types, the Monte Carlo method was used to extrapolate the survival duration beyond the follow-up limit of 180 months, initially for the whole sample, and then for each separate injury type (Hwang and Wang, 1999).

The extrapolation process comprised of three phases. First of all, from the life tables of the general population in Taiwan, the Monte Carlo simulation generated the survival duration for a reference population of gender- and age-matched individuals for each accident leading to an occupational injury. Secondly, a simple linear regression calculated the survival curve ratios, for both the index population and the reference populations, up to the end of the follow-up period. Finally, the estimated regression line and survival curve of the reference populations were used to project long-term survival values beyond the follow-up limit.

The standard error of the survival estimate was obtained through a bootstrap method. In order to facilitate the above computation, a statistical package MC-QAS, written in R and S-Plus software, was used (S-Plus, 2000). ${ }^{1}$

Using the 1995 Taiwan vital statistics and survival data for each accident as variables, the program estimated the mean survival duration for the subjects and the reference populations up to 600 months, along with the mean survival difference between the subjects and reference populations, which represented the expected months of life lost for each different injury event. In

\footnotetext{
1 The program is downloadable from the website: http://www.stat.sinica. edu.tw/jshwang/qas.htm.
}

order to test the validity of the Monte Carlo method, cases of occupational injury between 1986 and 1993 (a total of 96 months of follow-up) were extrapolated to 180 months based upon the Monte Carlo extrapolation and the parametric model approach under Weibull distribution, with the outcomes being compared with the real follow-up population in 2000 , the end of the 180month follow-up period.

The subtotal of EYLL for all cases of disability was calculated by multiplying the average EYLL by the number of claims for each injury event. For cases of mortality, the EYLL for both males and females were age-matched with the life expectancy of the general population of Taiwan for the particular calendar year.

As a result of the lack of an existing working life expectancy table, the YPWLL was computed for cases of both mortality and permanent disability using the 'life participation employment' (LPE) approach (Altmann, 1999). First of all, the average loss of expected working years was computed for each occupational injury, up to the age of 65 years, using the Monte Carlo method. Secondly, since there are variations with each business cycle in both the labor participation rate $(P)$ and the unemployment rate $(E)$ for both males $(P=0.748-0.694 ; E=0.033-0.014)$ and females $(P=0.443-0.461 ; E=0.025-0.015)$, the $P$ and $E$ values were assumed to be constant, based on averages over the followup periods by gender, that is, $P=0.72$ and $E=0.018$ for males and $P=0.45$ and $E=0.018$ for females.

Thirdly, we calculated the product of the expected years of working life lost (combining $P \times E$ into a probability of being employed if alive) multiplied by the number of cases for the different types of injury event. Finally, the averages of EYLL and YPWLL per $10^{5}$ working years, for both permanent disability and mortality, were also calculated as an indicator of the health impact from different types of work-related accidents leading to injury between 1986 and 2000.

\section{Results}

The calculations of the frequency distributions of permanent disabilities for the 10 different types of work-related injury event, between 1986 and 2000, are presented in Table 1, which shows that there was significant asymmetric distribution. 'Compressed by equipment' accounted for up to $68.1 \%$ of all injuries followed by 'cuts, lacerations or punctures by equipment' at $6.7 \%$ and 'transportation accidents' at $6.0 \%$.

The age of onset for cases of 'collapse/tumble down' and cases of 'slips/trips' was significantly higher than that for other accidents, whilst, 'compressed by equipment' and 'contact with electric current' often occurred at an earlier age. An additional nine different types of occupational injuries, each with small sample sizes (less than 300 cases each), were combined into a separate category in Table 1, renamed as 'not elsewhere classified' (NEC). This category included occurrences of deaths from drowning, explosions, fire injuries, injuries from contact with extreme temperature and so on. However, the standard deviation on the age of onset for all of the different injury events was in excess of 10 years, indicating considerable variation in the ages of those involved in these accidents. 
Table 1

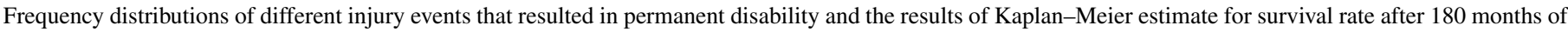
follow-up

\begin{tabular}{|c|c|c|c|c|}
\hline Injury events & No. of cases $(\%)$ & Onset age mean \pm S.D. (years) & No. of deaths & Kaplan-Meier estimate \\
\hline Compressed by equipment & $55351(68.1)$ & $36.0 \pm 12.2$ & 2285 & 0.916 \\
\hline Cuts, lacerations and punctures by equipment & $5426(6.7)$ & $38.0 \pm 12.4$ & 295 & 0.879 \\
\hline Transportation incidents & $4896(6.0)$ & $40.4 \pm 12.1$ & 378 & 0.813 \\
\hline Struck by sliding objects & $1671(2.1)$ & $43.4 \pm 11.7$ & 143 & 0.742 \\
\hline Collapse/tumble down & $1253(1.5)$ & $46.5 \pm 10.5$ & 172 & 0.739 \\
\hline Fall to lower level & $1571(1.9)$ & $42.5 \pm 11.0$ & 108 & 0.810 \\
\hline Struck by falling objects & $1205(1.5)$ & $41.9 \pm 11.7$ & 73 & 0.875 \\
\hline Slips/trips & $1104(1.4)$ & $46.7 \pm 11.1$ & 113 & 0.770 \\
\hline Contact with electric current & $413(0.5)$ & $36.6 \pm 10.9$ & 25 & 0.879 \\
\hline Struck against objects & $329(0.4)$ & $42.4 \pm 11.7$ & 12 & 0.898 \\
\hline Not elsewhere classified & $1619(2.0)$ & $42.1 \pm 12.1$ & 144 & 0.734 \\
\hline Not otherwise specified & $6411(7.9)$ & $39.5 \pm 12.7$ & 406 & 0.839 \\
\hline Overall & 81249 & $37.5 \pm 12.4$ & 4154 & 0.891 \\
\hline
\end{tabular}

Following 15 years of follow-up on workers with permanent disabilities, over $94 \%$ were either still alive or registered as suffering from all types of injury events. From the Kaplan-Meier estimations of the survival rates, which are presented in Table 1, we can see that 'collapse/tumble down' and 'struck by sliding/slipping objects' accidents display the lowest survival rates (0.734-0.742).

In order to validate our Monte Carlo method for extrapolation to lifetime survival, those cohorts established between 1986 and 1993 (96 months) were extrapolated for an additional 7 years. The actual data on 180 months of follow-up (1986-2000) was regarded as the 'gold standard' for comparison with the extrapolated estimated survival rate, with the results being summarized in Table 2.

The differences in survival ranged from 0.2 to 8.6 months, which revealed that when using the Monte Carlo method, none of the biases on different occupational injuries was over 5.3\%. Following 600 months of extrapolation, the differences between the survival curves for individuals 'struck by sliding/slipping objects' and the reference population, for 1995, are illustrated in Fig. 1. The difference in the areas beneath the two curves is

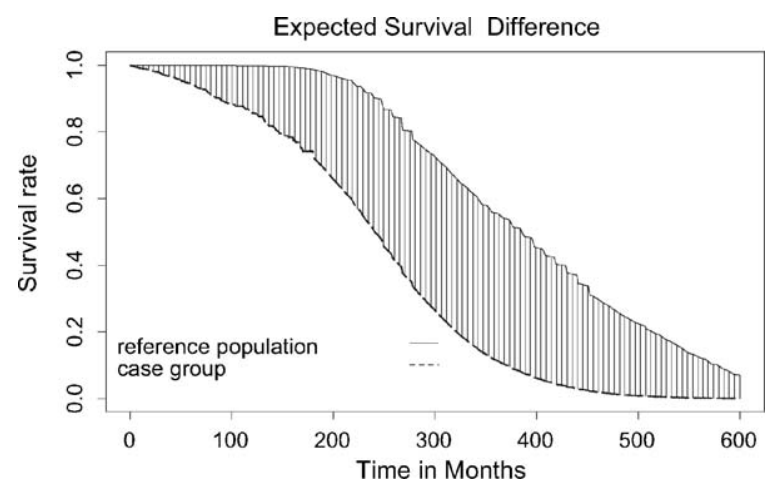

Fig. 1. Expected survival difference between cases of "struck by sliding/slipping objects" injury and the reference population after 600 months of extrapolation.

representative of the average impact on the EYLL for cases of permanent disability resulting from other types of injury events discussed in this study.

For permanent occupational disability, different types of injury event showed variations in the EYLL ranging from 7.4 to 13.6 years per case, as shown in Table 3 . As the table shows,

Table 2

Comparison between estimated survivals (months) based on Monte Carlo extrapolation and parametric model approach under Weibull distribution after 96 months of follow-up and actual mean survival (months) after 180 months of follow-up for the cohort of permanent disability which occurred in 1986-1993

\begin{tabular}{|c|c|c|c|c|}
\hline Injury event type & $\begin{array}{l}\text { Registered rates } \\
\text { after } 96 \text { months of } \\
\text { follow-up (\%) }\end{array}$ & $\begin{array}{l}\text { Estimated survival based on } \\
96 \text { months of follow-up and } \\
\text { extrapolated to } 180 \text { months } \\
\text { by Monte Carlo extrapolation }\end{array}$ & $\begin{array}{l}\text { Estimated survival based on } \\
96 \text { months of follow-up and } \\
\text { extrapolated to } 180 \text { months } \\
\text { under Weibull distribution }\end{array}$ & $\begin{array}{l}\text { Mean survival after } \\
180 \text { months of } \\
\text { follow-up for the } \\
\text { same cohort }\end{array}$ \\
\hline Compressed by equipment & 98.2 & $172.2 \pm 0.7$ & 173.7 & 172.4 \\
\hline Fall to lower level & 94.7 & $160.0 \pm 2.8$ & 160.7 & 158.2 \\
\hline Contact with electric current & 96.4 & $169.0 \pm 2.9$ & 163.2 & 168.4 \\
\hline Struck by sliding objects & 94.9 & $152.9 \pm 4.5$ & 153.8 & 161.5 \\
\hline Collapse/tumble down & 94.0 & $163.1 \pm 2.2$ & 164.9 & 160.3 \\
\hline Slips/trips & 95.1 & $151.8 \pm 3.8$ & 168.1 & 159.3 \\
\hline Struck by falling objects & 96.1 & $164.2 \pm 2.7$ & 166.3 & 167.6 \\
\hline Struck against objects & 98.2 & $171.9 \pm 12.1$ & 174.1 & 167.6 \\
\hline Not elsewhere classified & 94.3 & $161.1 \pm 5.0$ & 161.8 & 157.5 \\
\hline
\end{tabular}




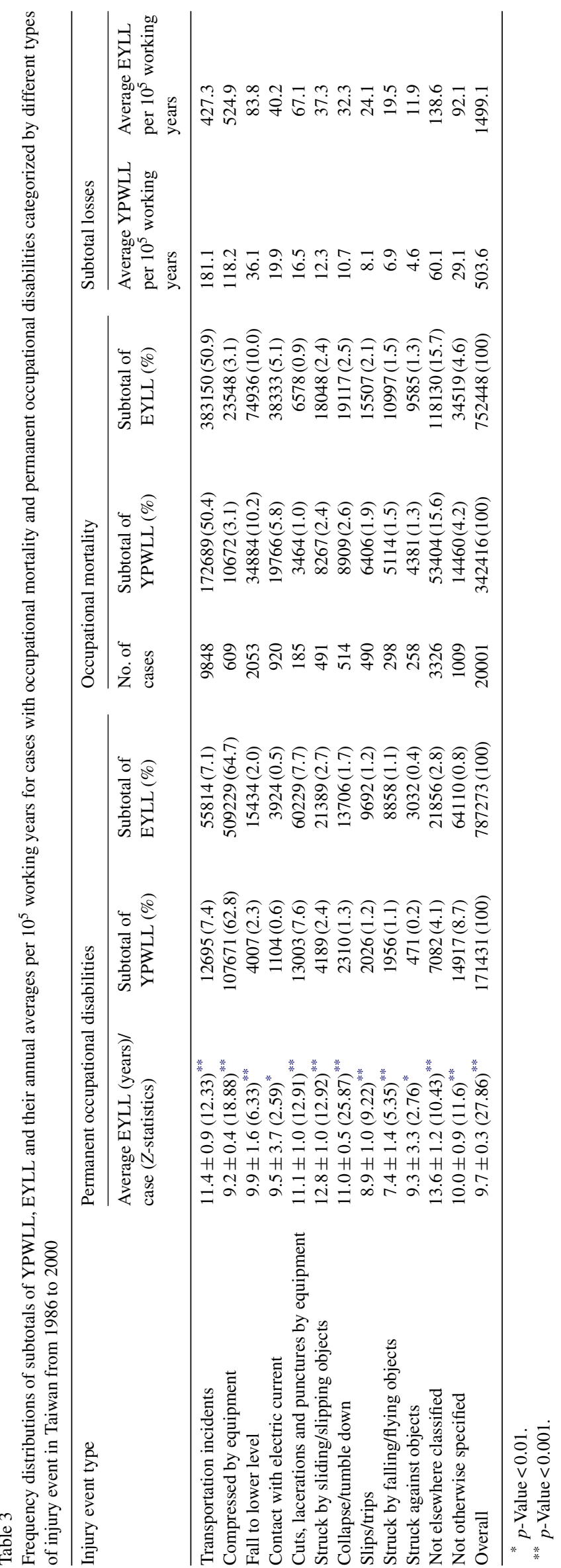

Table 4

Frequency distributions of life expectancies (in terms of years) for cases with permanent occupational disabilities compared with general population (referents) stratified by gender and onset age

\begin{tabular}{llllll}
\hline Age (years) & \multicolumn{3}{l}{ Male } & & Female \\
\cline { 2 - 3 } \cline { 5 - 6 } \cline { 5 - 6 } & Referents & $\begin{array}{l}\text { Cases (\% of } \\
\text { referents) }\end{array}$ & & Referents & $\begin{array}{l}\text { Cases }(\% \text { of } \\
\text { referents) }\end{array}$ \\
\hline $20-24$ & 47.7 & $42.4(89)$ & & 56.1 & $49.1(88)$ \\
$25-29$ & 43.8 & $37.4(85)$ & & 51.9 & $44.8(86)$ \\
$30-34$ & 40.9 & $33.0(81)$ & & 47.6 & $41.6(87)$ \\
$35-39$ & 36.7 & $29.8(80)$ & & 42.8 & $38.1(89)$ \\
$40-44$ & 32.3 & $26.7(83)$ & & 38.0 & $34.3(90)$ \\
$45-49$ & 28.3 & $22.6(80)$ & & 33.3 & $29.6(89)$ \\
$50-54$ & 22.4 & $19.3(86)$ & & 28.8 & $24.8(86)$ \\
$55-59$ & 18.9 & $16.5(87)$ & & 24.3 & $19.0(78)$ \\
$60-64$ & 16.2 & $13.7(85)$ & & 20.7 & $15.7(76)$ \\
$65-69$ & 13.5 & $11.8(87)$ & & 17.1 & $13.1(77)$ \\
\hline
\end{tabular}

Values in parenthesis are given in percentage.

when the EYLL of the different types of occupational injuries is compared with the reference population, using the $Z$-test, significant differences were found for all types. The frequencies of the YPWLL and the EYLL for each type of injury event were also combined to produce subtotals. Ignoring the injury events listed as NEC, the highest average EYLL per case was for 'struck by sliding/slipping objects' accidents, whilst 'compressed by equipment' had the largest subtotal of EYLL, accounting for about two-thirds of all injuries.

With regard to occupational mortality, from the distribution of the YPWLL and EYLL subtotals presented in Table 3, injuries resulting from 'transportation accidents' dominated, accounting for $50.4 \%$ of YPWLL and $50.9 \%$ of EYLL. The average EYLL and YPWLL rates covering a period of 15 years, which were obtained from a combination of both permanent disability claims and mortality claims, are presented in Table 3.

Table 3 also reveals that within the YPWLL rates, cases of 'transportation accidents', 'compressed by equipment', and 'fall to lower level' were the leading causes. Nevertheless, due to the enormous EYLL rates involving cases of permanent disability, the average EYLL for 'compressed by equipment' injury events attained a value of 524.9 per $10^{5}$ working years. Overall, between 1986 and 2000, the annual average for YPWLL per $10^{5}$ working years, was 503.6, whilst the average for EYLL per $10^{5}$ working years, was 1499.1.

Our results indicate that the mortality rate for those who survive the acute care phase, but who subsequently suffer from permanent disability, is higher than that of the general population, with the same age and gender. Table 4 compares the mean life expectancies for those with and without permanent disabilities. After pooling all of the different injury events, the magnitude of the reduction in life expectancy was more prominent amongst young workers and females.

\section{Discussion}

Despite the limited availability of background knowledge, this study represents the first of its kind to attempt to investigate 
the premature mortality of workers suffering from permanent disabilities as a direct result of occupational injuries. The overall EYLL from permanent occupational disabilities was, in fact, almost the same as that of occupational mortalities, with a ratio of 1.04:1. Assuming a uniform retirement age of 65 years, but without counting the loss of working ability, the YPWLL as a result of permanent occupational disabilities was approximately $50 \%$ of that resulting from occupational mortalities.

These figures indicate significant human capital loss resulting from permanent occupational disabilities (Sheu et al., 2000; Linn and Sheps, 1993). Between 1986 and 2000, there were approximately 34,000 YPWLL and 100,000 EYLL each year as a result of serious occupational injuries in Taiwan. It would therefore seem highly desirable to take proactive measures now, to prevent similar losses in the future.

\subsection{Validity of the Monte Carlo extrapolation method}

Although the traditional Kaplan-Meier estimator is unable to determine lifetime survival rates when the follow-up period is short, and when the rate of registration is high (as shown in Table 1), this study has provided an estimation for both lifetime extrapolation and years of life lost based on a comparison with an age- and gender-matched general population. However, the accuracy and precision of our estimates for long-term survival require an empirical validity test, as well as a comparison with a parametric model, such as under Weibull distribution.

The simulation results based on the Monte Carlo method (presented in Table 2) demonstrated that a projected 180 months of survival was generally accurate, with only small relative biases of $0.1-5.3 \%$, and a tendency towards reduction in the standard errors with an increase in the duration of the follow-up and the sample size. Similar results were also observed in Table 2 when the same cohort was extrapolated to 180 months under the Weibull model.

Any comparison of different YPLL would have been inappropriate in the past, unless assuming a uniform terminal age; for example, premature death has invariably been defined as death at the age of less than 65 or 75 years (or less than the average life expectancy) (Rodriguez-Acosta et al., 1999). However, a survival analysis, or a life table analysis, examines the life expectancy of survivors as they age, with the life expectancy for those who survive to a given age obviously exceeding the life expectancy for the overall population, including those who may well have died at an earlier age. As a result, the use of a procedure with a uniform terminal age, such as YPWLL estimates (but with a different cut-off age at death from that of the termination of working life age, at 65 years) would clearly underestimate the EYLL, and would also probably underestimate YPWLL, as the retirement age may be postponed.

The Monte Carlo estimation method used in this study actually simulates, from the vital statistics, an age- and gender-specific reference person for every case of mortality. Therefore, through the use of this method, we can obtain a more accurate estimate of EYLL than under the traditional method of assuming an arbitrary terminal age. According to the estimations in Table 3, for cases of occupational mor- tality, the total YPWLL was about one-half that of EYLL $(342,416 / 752,448=0.46)$, whilst for cases of permanent disability, the ratio of YPWLL/EYLL was only 0.22 . Both of these ratios indicate that, in terms of payment of worker compensation, if there had been no backup social security system as in Taiwan, a major proportion of the losses occurring after retirement age may have been ignored. Therefore, for the most severe cases, the financial burden may be quite heavy after retirement, when daily care is required to support the activities of normal daily life.

Despite having access to the best available data in Taiwan, there are certain limitations of this study that could result in slight underestimation of both the EYLL and the YPWLL. First of all, for the whole of the 15-year follow-up period, $4.7 \%$ of mortality cases were not successfully linked to the national death registry, which implies that whilst some of those suffering from permanent disabilities may have died during the follow-up period, they were unrecorded, and will have consequently contributed to underestimation of the EYLL. Secondly, there will generally be an increase in life expectancy as a result of ongoing developments in healthcare technology; therefore, it should be expected that the surviving cases with permanent disability in this study have a gradually increasing life expectancy.

Thirdly, this study did not include occupational injury cases resulting in either total or partial disability of a temporary nature, or those cases resulting in no disability at all. In order to gain a clearer picture of the impact of temporary disability in Taiwan, we estimated the number of working days spent on sick leave with regard to YWLL (years of working life lost), and also estimated the number of working days spent on sick leave as a result of temporary disability; the mean annual estimate between 1986 and 2000 was about 5909.2. ${ }^{2}$ It is apparent, therefore, that the overall impact of serious injuries is generally greater than that for temporary disabilities; however, the estimated YPWLL only reflects the lower bound of overall health impacts in Taiwan resulting from occupational injuries.

Finally, health-related quality of life was not considered in this study, which also limits the results of this study with regard to their further application in cost-utility analysis based on welfare economics (Fabian, 1994).

\subsection{Policy implications for occupational health and safety}

Adopting the common units of EYLL and YPWLL, the results of this study provide crucial information on the development of priorities for occupational accident prevention. The

\footnotetext{
2 In Taiwan, cases of work-related temporary disability resulting in hospital stays in excess of 3 days are eligible for compensation claims to cover loss of income as a result of working days on sickness leave. The compensation provides $70 \%$ of the daily income losses from the fourth day of sickness leave. A total of 434,744 claims were made between 1986 and 2000, amounting to $25,287,364$ days of compensation payments. We assume that 300 working days is approximately equivalent to 1 year of working life in Taiwan. Therefore, the grand total of sick leave working days for temporary disability cases was $26,591,596$ (i.e. $434,744 \times 3+25,287,364$ ), giving an annual estimate of 5909.2 years of working life lost. As compared with the estimated annual YPWLL of cases of permanent disability, the ratio was about 0.52 (5909.2/11428.7).
} 
averages of both YPWLL and EYLL showed similar trends on the impacts of different injury events. 'Compressed by equipment' injuries led to the highest loss of average EYLL per $10^{5}$ working years, with the annual occurrence of 3,690 new cases over the last 15 years.

Based upon BLI annual report statistics, most transportation accidents ( $80 \%$ on average) occur whilst commuting to and from the workplace (BLI, 2004); however, in many countries, including the US, transportation accidents which occur whilst commuting are not included in worker compensation coverage, although they are included as compensatory elements for occupational accidents in Taiwan. Our study has shown that transportation accidents whilst commuting were the second most serious problem amongst all occupational accidents; however, since much of the commuting in Taiwan is by motorcycles, enforcement of the helmet law for motorcycle riders, which began in 1997, has significantly reduced the number of head injuries resulting from traffic accidents (Tsauo et al., 1999; Chiu et al., 2000).

Injuries from 'fall to lower level' occurred mainly on construction worksites, with an average of 24.5 EYLL for mortality cases and 10 EYLL for cases of permanent disability. It would probably be quite cost-effective, therefore, to simply enforce the use of currently available means of fall prevention, including safety belts and scaffolding, at all construction sites (Yassin and Martonik, 2004).

This study provides a further empirical basis for improving the labor insurance compensation system, particularly with regard to wage compensation for mortality and serious permanent disability. For mortality cases, the current system in Taiwan pays only a lump sum of up to 45 months salary to the families of deceased workers, and although the government is currently planning to change this into a monthly payment system, uncertainty surrounding the financial burden for different severity of injuries is hindering the decision-making process. However, the results of the extrapolation of survival rates in this study can clearly provide useful information for actuarial calculation. Moreover, since the premiums in the worker compensation system are merit-based, such information should also prove to be important in the calculation of the premiums for different types of occupational injuries, ultimately improving both equity and efficiency.

\section{Conclusions}

The life expectancy for those who survive the acute care phase of occupational injuries, but who subsequently suffer permanent disabilities, is found to be shorter than that of the general population with the same age and gender. In addition to mortality, permanent disability resulting from occupational injuries has a significant impact on society.

The EYLL for permanent occupational disability is found to be virtually the same as the EYLL for mortality, whilst the YPWLL for permanent occupational disabilities was about onehalf the YPWLL for mortality. Such estimations could provide an empirical basis for both the implementation of proactive prevention, and improvements in the equity and efficiency of the workers compensation system in Taiwan.

\section{Acknowledgements}

This article was partially supported by the Institute of Occupational Safety and Health (grant no. IOSH91-E101) and the National Health Research Institutes (grant no. NHRI-EX959204PP), Taiwan.

\section{References}

Asikainen, I., Kaste, M., Sarna, S., 1996. Patients with traumatic brain injury referred to a rehabilitation and re-employment programme: social and professional outcome for 508 Finnish patients 5 or more years after injury. Brain Injury 10 (12), 883-899.

Altmann, J.L., 1999. The interdependence of " $P$ " and " $E$ " in the LPE methodology: a caution to users about possible bias. J. Forensic Econ. 12 (3), 177-184.

Boden, L.I., Biddle, E.A., Spieler, E.A., 2001. Social and economic impacts of workplace illness and injury: current and future directions for research. Am. J. Ind. Med. 40 (4), 398-402.

Bureau of Labor Insurance (BLI), 2004. Statistical Data for Taiwan-Fukien Area Labor Insurance Republic of China 2003. Bureau of Labor Insurance, Taipei, Taiwan.

Chang, Y.C., Wang, J.D., 1995. Cumulative injury rate and potential workdays and salary lost. Scand. J. Work Environ. Health 21 (6), 494-503.

Chang, Y.C., Wang, J.D., 1997. Trends in major occupational injuries in different industrial divisions in Taiwan during 1983-1993. J. Occup. Health 39, 295-301.

Council of Labor Affairs (CLA), 2004. Yearbook of Labor Statistics Taiwan Area, Republic of China 2003. Council of Labor Affairs, Taipei, Taiwan.

Chiu, W.T., Kuo, C.Y., Hung, C.C., Chen, M., 2000. The effect of the Taiwan motorcycle helmet use law on head injuries. Am. J. Public Health 90 (5), 793-796.

Dembe, A.E., 2001. The social consequences of occupational injuries and illness. Am. J. Ind. Med. 40 (4), 403-417.

Dempsey, M., 1947. Decline in tuberculosis: the death rate fails to tell the entire story. Am. Rev. Tuberc. 48, 369-374.

Department of Labor (DOL), 2003. State Workers' List of Benefit Tables. Department of Labor, Employment Standards Administration, Office of Workers' Compensation Programs, Washington, DC. Retrieved October 8, 2004, from: http://www.dol.gov/esa/regs/statutes/owcp/ stwclaw/stwclaw.htm.

Fabian, R., 1994. The Qualy approach. In: Tolley, G., Kenkel, D., Fabian, R. (Eds.), Valuing Health for Policy: An Economic Approach. University of Chicago Press, Chicago, IL.

Herbert, R., Landrigan, P.J., 2000. Work-related death: a continuing epidemic. Am. J. Public Health 90, 541-545.

Horan, J.M., Mallonee, S., 2003. Injury surveillance. Epidemiol. Rev. 25, 24-42.

Hsieh, G.Y., Chen, P.C., Wang, J.D., 2002. Verification and correction of error for death registration data of the Department of Health R.O.C. between 1980 and 1997. Taiwan J. Public Health 21 (5), 329-338.

Hwang, J.S., Wang, J.D., 1999. Monte Carlo estimation of extrapolation of quality-adjusted survival for follow-up studies. Stat. Med. 18, 1627-1640.

Lee, W.C., 1997. Quantifying the future impact of disease on society: life table-based measures of potential life lost. Am. J. Public Health 87 (9), 1456-1460.

Leigh, J., Macaskill, P., Kuosma, E., Mandryk, J., 1999. Global burden of disease and injury due to occupational factors. Epidemiology 10 (5), 626-631.

Leigh, J.P., Markowitz, S.B., Fahs, M., Shin, C., Landrigan, P.J., 1997. Occupational injury and illness in the United States. Arch. Intern. Med. 157, 1557-1568

Linn, S., Sheps, S., 1993. Disability and the years of potential productivity lost: modifying the years of potential life lost and the investment-production-consumer model by disability level. Epidemiology $4,449-454$. 
McColl, M.A., Walker, J., Stirling, P., Wilkins, R., Corey, P., 1997. Expectations of life and health among spinal cord injured adults. Spinal Cord 35 (12), 818-828.

McDonnell, S., Vossberg, K., Hopkins, R.S., Mittan, B., 1998. Using YPLL (years of potential life lost) in health planning. Public Health Rep. 113 (1), 55-61.

Murray, C.J.L., Mathers, C.D., Salomon, J.A., Lopez, A.D., 2002. Health gaps: an overview and critical appraisal. In: Murray, C.J.L., Salomon, J.A., Mathers, C.D., Lopez, A.D. (Eds.), Summary Measures of Population Health: Concepts, Ethics, Measurement and Applications. World Health Organization, Geneva, Retrieved December 10, 2004, from: http://whqlibdoc.who.int/publications/2002/9241545518.pdf.

National Institute for Occupational Safety and Health (NIOSH), 2000. Worker Deaths by Falls: A Summary of Surveillance Findings and Investigative Care Reports. National Institute for Occupational Safety and Health, Cincinnati, OH, DHHS (NIOSH) publication no. 2000-116.

National Institute for Occupational Safety and Health (NIOSH), 2001. Fatal Injuries to Civilian Workers in the United States, 1980-1995 (National and State Profiles). National Institute for Occupational Safety and Health, Cincinnati, OH. DHHS (NIOSH) publication no. 2001-129S. Retrieved December 12, 2004, from: http://www.cdc.gov/niosh/NTOF2000/ 2001129state.html.

Pratt, S.G., Kisner, S.M., Helmkamp, J.C., 1996. Machinery-related occupational fatalities in the United States, 1980 to 1989. J. Occup. Environ. Med. 38 (1), 70-76.

Rodriguez-Acosta, R., Emery, J., Wolf, S.H., Richardson, D., 1999. Fatal Occupational Injuries in North Carolina: Databook. UNC Injury Prevention Research Center, Chapel, NC.
SAS, 2002. Release 8.02 (Computer Program). SAS Institute, Cary, NC.

Segui-Gomez, M., Mackenzie, E.J., 2003. Measuring the public health impact of injuries. Epidemiol. Rev. 25, 3-19.

Sheu, J.J., Hwang, J.S., Wang, J.D., 2000. Diagnosis and monetary quantification injuries by indices related to human capital loss: analysis of a steel company as an illustration. Accid. Anal. Prev. 32, 435-443.

S-Plus, 2000. Professional Release 3 (Computer Program). MathSoft Inc.

Takala, J., 1999. Global estimates of fatal occupational accidents. Epidemiology 10, 640-646.

Thompson, C., Reno, V., Mont, D., Burton, J.F., Thomason, T., 2002. Workers' compensation coverage. Workers Compens. Policy Rev. 2 (5), 13 18

Toscano, G., Windau, J., Drudi, D., 1996. Using the BLS occupational injury and illness classification system as a safety and health management tool Compens. Work. Cond. June, 1996, 19-23. Retrieved December 20, 2004 , from: http://www.bls.gov/opub/cwc/archive/summer1996art3.pdf.

Tsauo, J.Y., Hwang, J.S., Chiu, W.T., Hung, C.C., Wang, J.D., 1999 Estimation of expected utility gained from the helmet law in Taiwan by quality-adjusted survival time. Accid. Anal. Prev. 31, 253263.

Weil, D., 2001. Valuing the economic consequences of work injury and illness: a comparison of methods and findings. Am. J. Ind. Med. 40 (4), 418-437.

Yassin, A.S., Martonik, J.F., 2004. The effectiveness of the revised scaffold safety standard in the construction industry. Saf. Sci. 42, 921-931.

Zwi, A.B., Forjuoh, S., Murugusampillay, S., Odero, W., Watts, C., 1996. Injuries in developing countries: policy response needed now. T. R. Soc. Trop. Med. H. 90, 593-595. 